\title{
A INFINDÁVEL GUERRA AMERICANA Brasil, EUA e o narcotráfico no continente
}

THIAGo M. S. RodRigues

Resumo: Os discursos governamentais nas Américas investem, em uníssono, em uma política de combate ao tráfico e ao uso de substâncias ilegais. Na esteira do consenso político e econômico atual, o combate ao narcotráfico alinha posturas repressivas em todo o continente. Este artigo trata do diálogo existente entre o proibicionismo brasileiro e norte-americano, acompanhando matizes históricos e práticas contemporâneas. Palavras-chave: narcotráfico; proibicionismo; política externa norte-americana.

Abstract: The governments of North, South and Central America are unanimous in their strong anti-drug policies. Hemispheric consensus currently exists in both the political and economic spheres, in favor of a harsh approach to combating narcotrafficking. This article attempts to examine the relationship between the Brazilian and American versions of prohibitionism, placing it in its historical context and reviewing contemporary approaches.

Key words: narcotraffic; prohibitionism; United States foreign policy.

É preciso encontrar a guerra: ela é a cifra da paz.

Michel Foucault

$\mathrm{O}$ consenso democrático - que irmana práticas políticas e discursos governamentais no continente americano da passagem do século $\mathrm{XX}$ ao XXI - dialoga com outro tema de unívoca concordância: o combate ao narcotráfico. Presente nos mais diversos ambientes diplomático-administrativos continentais, a discussão sobre a "guerra às drogas" assume posição de destaque nas agendas dos Estados americanos, tanto no plano das políticas de segurança nacionais quanto nas de segurança coletiva. A preocupação maior do discurso político americano contemporâneo, a manutenção da democracia, emerge umbilicalmente relacionada a fatores tão condicionantes quanto vagos, como o "fortalecimento das instituições", a "defesa dos direitos humanos" e a "liberalização dos fluxos comerciais e financeiros". Conquanto tais matérias causem debates por vezes acirrados entre grupos econômicos, governos e setores sociais das Américas, há outro ponto vinculado à "manutenção da paz so- cial" que não causa tamanha celeuma. Trata-se, justamente, da unanimidade em torno da urgência em se combater o tráfico de drogas nos países da região. Amparada em lastros morais, escorando-se também em saberes médicosanitários, a luta contra o narcotráfico é acionada politicamente quando o próprio tráfico de drogas é içado ao posto de maior antígeno a "infectar" e "corromper" a vida social e institucional dos Estados neodemocráticos. $\mathrm{O}$ narcotráfico, considerado o amálgama que congrega e patrocina diversas manifestações da criminalidade organizada, passa a ser alvo de Estados que não discutem tãosó a internacionalização de suas economias, mas que investem no enrijecimento harmônico das políticas de repressão à produção, tráfico e consumo de drogas. ${ }^{1}$

Dentro de um campo vasto como este que cerca o narcotráfico, este artigo propõe um foco bem definido e que, de modo explícito, nega pretensões normativas ou entra em disputas por supremacias cognitivas. Diante de questões referentes à constituição de blocos econômicos regionais ou continentais e de outras discussões que recebem feições supranacionais, ${ }^{2}$ cabe lançar um olhar, ainda que parcial, sobre a postura brasileira no que concerne tanto ao combate estatal ao tráfico quanto às atividades levadas 
a cabo por empresas narcotraficantes no Brasil e sobre os veios de comunicação entre o proibicionismo dos Estados Unidos e a postura repressora brasileira, lançando mão, para tanto, de uma breve análise genealógica do tráfico e das leis antidrogas brasileiras e norte-americanas.

\section{ECOS NO PRESENTE}

Nos anos iniciais do século XX, os brados moralistas que se faziam ouvir nos Estados Unidos desde meados do século anterior passam a reverberar nas altas esferas políticas estadunidenses. O puritanismo organizado norteamericano $^{3}$ conseguira, então, levar seus homens às instâncias representativas, ao tempo em que as práticas governamentais do Estado aceleravam a marcha das medidas de controle social com base no rastreamento de hábitos e na disciplinarização de condutas. Apesar do crescimento dos movimentos sociais proibicionistas, o cenário privilegiado para os primeiros passos repressivos do Estado norte-americano não foi o ambiente político doméstico, mas o teatro das negociações diplomáticas. O governo dos Estados Unidos logra seus êxitos iniciais no controle de drogas nas reuniões internacionais que convoca. A primeira, realizada em Xangai, em 1909, não chega a elaborar determinações impositivas aos países signatários (países que contavam com fortes indústrias farmacêuticas e com monopólios comerciais na Ásia, Inglaterra e Alemanha), mas constrange essas mesmas potências internacionais que, ao contrário dos EUA, interessavam-se pelo lucrativo mercado do uso hedonista do ópio e seus derivados. ${ }^{4}$

A próxima conferência patrocinada pelos Estados Unidos aconteceu em Haia, Holanda, em dezembro de 1911. O documento, assinado em janeiro de 1912, satisfez os diplomatas estadunidenses ao fixar determinações específicas que obrigavam os Estados signatários a coibir, em seus territórios, todo uso de opiáceos e cocaína que não atendessem recomendações médicas. Limites científicos, provenientes do saber médico que se construía então e que ganhava legitimidade pela chancela estatal, parametrando e justificando a necessidade de se proibir o "uso indiscriminado" de substâncias "alteradoras do comportamento". Importante destacar o fato de que ao defender medidas severas de controle no plano internacional, o governo estadunidense não estava defendendo uma internacionalização de sua lei nacional. Pelo contrário, não havia no ordenamento interno norte-americano lei semelhante ao Tratado de Haia; o que de fato ocorreu foi a utilização pelo governo norte-americano de uma tática depois recorrente que consistiu em usar normas acordadas internacionalmente como instrumento para pressionar reformas legais internas. No momento em que o acordo de Haia era assinado, transitava pelo Congresso norte-americano uma proposta de lei que previa não mais a mera fiscalização estatal, mas a efetiva proibição do livre consumo de opiáceos e cocaína. O cumprimento do acordo internacional só poderia dar-se com a adequação do código interno estadunidense, o que afinal ocorreu em 1914 com a promulgação da Harrison Act. ${ }^{5}$

As resistências das alas políticas liberais, calcadas na idéia de que o uso de drogas era questão de foro íntimo, vão sendo minadas ao longo da década de 10 até que, em 1919, a antiga reivindicação proibicionista (a supressão do álcool) cristaliza-se em lei federal. A $18^{\text {a }}$ Emenda à Constituição proibia a produção, transporte, importação e exportação de bebidas alcoólicas em todos os Estados da federação. A década seguinte principia com um gigantesco mercado ilegal criado pela Lei Seca, circundado por circuitos clandestinos relacionados a outras drogas proibidas como a cocaína. O aparato burocrático-repressivo cresce desmesuradamente para tentar dar conta das atividades ilegais e de pessoas (negros e imigrantes chineses, mexicanos, irlandeses e italianos) lançadas nesses ambientes de marginalidade. No plano internacional, os EUA mantêm a postura de enunciadores de políticas repressivas que são, em linhas gerais, tomadas como base dos tratados internacionais firmados desde então.

Ao sul, o Brasil deste início de século também assistia a emergência e a complexificação de códigos sanitários destinados à profilaxia e à higienização sociais. O Código Sanitário da República, editado em 1890, preocupavase com a disciplinarização do espaço urbano o que equivalia, entre outras medidas, à remodelagem das cidades segundo padrões europeus e à imunização compulsória da população. O tema do controle de substâncias psicoativas entrava tangencialmente na pauta sanitária, e a venda e o uso desses produtos não eram, até a década de 10 , passíveis de qualquer controle estatal. Havia a condenação pública do uso de drogas por jornais conservadores e grupos moralistas como a Loja Cruzeiro do Sul; contudo, a prática da intoxicação foi tolerada enquanto fez parte do mundo dos prostíbulos chics freqüentados pelos jovens filhos da oligarquia da República Velha. No início da década de 20, contudo, a situação modificara-se. De um lado, o Brasil havia-se comprometido na Convenção de Haia a fortalecer o controle sobre opiáceos e cocaína, o que de 
fato nunca fizera; de outro, os "vícios elegantes" dos rapazes finos logo perderam a aura romântica perante os olhos governamentais ao se disseminarem entre as "classes perigosas", ou seja, entre negros, pardos, imigrantes e toda a plebe urbana nacional (Carneiro, 1993). Assim, em 1921, surge a primeira lei restritiva na utilização de ópio, morfina, heroína e cocaína no Brasil. Seguindo o modelo de Haia (preconizado pelos Estados Unidos), a lei brasileira previa punição para todo tipo de utilização dessas substâncias que não seguisse prescrições médicas. O Brasil compareceria a todas as outras convenções plenipotenciárias sobre controle de drogas, assinando acordos e reformando seu ordenamento interno mediante ratificação dos compromissos internacionais.

Estar alinhado às determinações acordadas nos encontros internacionais significava, em larga medida, estar sintonizado com a postura proibicionista defendida pelos Estados Unidos; postura que se pautava pela proibição total à livre produção, circulação e consumo de substâncias psicoativas e pela repressão cerrada aos segmentos sociais associados (em parte pela prática, em parte pelo discurso governamental) ao tráfico de drogas. Se os encontros internacionais dos anos 1920 e 1930 foram ciceroneados pela Liga das Nações, após a Segunda Grande Guerra tais reuniões continuaram a se dar no âmbito da Organização das Nações Unidas (com seus organismos especializados), sempre contando com a incitação estadunidense. O Brasil, assíduo freqüentador dessas reuniões, pauta o ritmo de suas sucessivas reformas legais na matéria, seguindo as determinações acordadas nesses encontros. O procedimento de ratificação de tratados, ato de incorporação de um acordo internacional ao ordenamento legal nacional, foi instrumento primordial utilizado para atualizar as disposições vigentes no País, incrementando o corpo normativo e, conseqüentemente, fornecendo ao Estado maiores artifícios para acionar de maneira ainda mais enfática os aparatos de coerção ao tráfico e, em particular, aos traficantes.

Pode-se ilustrar essa postura brasileira, calcada na lógica da reforma interna motivada por acordos externos, por meio de dois exemplos: o Decreto-Lei n. 891 - 1938, editado pelo Estado Novo de Getúlio Vargas, sofisticava as determinações antidrogas vigentes no País desde a lei de 1921, baseando-se nos documentos assinados nas convenções de Genebra de 1931 e 1936; ${ }^{6}$ a reforma da lei sobre tóxicos de 1967 deu-se na esteira da incorporação ao ordenamento jurídico brasileiro da Convenção Única sobre Entorpecentes, o mais completo documento proibi- cionista de abrangência internacional assinado na sede da ONU em 1961. ${ }^{7}$ O moto contínuo das reformas prossegue com a edição da Lei de Tóxicos, Lei n. 6.386 - 1976, compilação e ampliação de determinações anteriores e que, com alguns ajustes posteriores, permanece em vigor no Brasil ainda que esteja na iminência de ser reescrita sob moldes mais contemporâneos. ${ }^{8}$

\section{MORROS E SELVAS: RASTROS}

Alguns assaltos a bancos muito bem executados fizeram com que circulasse na imprensa carioca, em meados de 1981, a sugestão de que, após a anistia política, as guerrilhas urbanas haviam-se rearticulado. O sensacionalismo midiático cede ao peso de constatação ainda mais alarmante: não era a contestação armada que ressurgia, mas o crime comum que anunciava sua transformação. A Lei de Segurança Nacional de 1968 havia equiparado sob a mesma tipificação assaltantes e seqüestradores comuns e guerrilheiros urbanos, dupla tentativa do governo militar em desqualificar os atos da esquerda e de capturar sob uma lei de exceção pessoas provenientes das "classes marginais e perigosas". Isolados em uma mesma ala da penitenciária de segurança máxima da Ilha Grande, assaltantes comuns e guerrilheiros urbanos partilharam saberes. Anistiados no governo Geisel, os guerrilheiros deixam a Ilha Grande, em 1975. A anistia, todavia, não é tão geral e irrestrita a ponto de liberar criminosos comuns (ainda que eles hajam sido condenados pela mesma lei dos "perdoados"). Os que permanecem encarcerados usam táticas de organização aprendidas com os guerrilheiros para sobreviver às outras facções que dominam o complexo carcerário. Organizam um grupo de autodefesa chamado Falange Vermelha, mas que pouco depois seria definitivamente batizado de Comando Vermelho.

No começo dos anos 80, o Comando Vermelho conquista o circuito penitenciário do Estado do Rio de Janeiro e ganha as ruas após inúmeras fugas de filiados. Grupos de assalto a bancos são formados por antigos assaltantes presos pela Lei de Segurança Nacional e que, de novo em liberdade, tentaram atualizar a prática com conhecimentos acumulados na partilha de saberes da Ilha Grande. A fase dos assaltos a bancos, contudo, é efêmera. O Comando Vermelho, organizado no sistema carcerário e nos morros cariocas, passaria logo a outro negócio, mais rentável e, então, em franca expansão: o tráfico de drogas. 
O aumento da demanda por cocaína nos Estados Unidos e Europa, na passagem dos anos 70 para os 80, potencializara o tráfico de drogas nos países andinos, transformando um negócio ilegal ainda de proporções modestas em grande empreitada empresarial. Na Colômbia, despontam grupos que, por acumularem tradição em práticas ilegais (tráfico de maconha, esmeraldas, seqüestros e contrabando), detêm os contatos e conexões fundamentais para sintetizar a cocaína e transportá-la aos centros consumidores (estadunidenses, europeus e latino-americanos). Essas empresas narcotraficantes, como a de Pablo Escobar e a dos irmãos Rodríguez Orejuela, concentram em suas mãos a fase da transformação da pasta-base em cocaína pura e da venda de grandes carregamentos da droga para atacadistas internacionais. A pasta-base, etapa inicial da produção de cocaína (quando as folhas de coca são maceradas e tratadas com produtos químicos até formar uma massa), era naquele momento produzida sobretudo na Bolívia e no Peru, países com áreas de tradicional cultivo da coca que, com a emergência do negócio do tráfico ilegal, passaram a produzir excedentes destinados ao narcotráfico. Nessa cartografia do narcotráfico latino-americano do começo dos anos 80, o Brasil desponta como rota fundamental para o escoamento da cocaína, com suas regiões selvagens como locus privilegiado para centros de apoio logístico e com sua indústria química como fornecedora de insumos necessários ao fabrico da cocaína.

O mercado da cocaína apresentava-se como uma ampulheta deitada, ${ }^{9}$ e as bases povoadas por, em um extremo, grupos em disputa pela fase inicial da transformação das folhas de coca em pasta-base e noutro pelo semnúmero de organizações que, em disputa cotidiana e violenta, competem pelos territórios varejistas. A estreita passagem da ampulheta representaria justamente a fase de transformação da pasta-base em cloridrato de cocaína, etapa dominada por poucas empresas ilegais. Aplicando a reflexão de Krauthausen e Sarmiento (1991) sobre a economia ilegal do tráfico à imagem acima apresentada, o gargalo da ampulheta representaria o setor oligopólico, constituído pelos poderosos grupos ilegais como o de Escobar, que evitam embates diretos entre si, dominam o conhecimento sobre as redes de distribuição internacionais e mantêm fortes laços simbióticos com o Estado e suas instituições; as bases da ampulheta ilustrariam, por seu lado, os setores competitivos do mercado da droga, ambientes nos quais os embates são violentos e constantes.

O Comando Vermelho apresenta-se, então, como uma organização inserida nessa dinâmica internacional do nar- cotráfico, ocupando lugar de destaque no setor competitivo brasileiro, ao disputar e, de fato, dominar, o varejo do mercado de drogas no Rio de Janeiro da década de 80. Organização que fixa sua autoridade nas favelas cariocas conjugando assistencialismo e coerção, fórmula maquiavélica da manutenção do poder que alia admiração, respeito, dependência e medo. As áreas dominadas por chefes ligados ao Comando Vermelho tornaram-se alvéolos de autoridade; autoridade exercida pelo "dono do morro" que impõe suas próprias normas e táticas de disciplinarização da população local. Como um "Estado-caricatura", o morro dominado pelo Comando Vermelho exibia manifestações próprias de gestão da conduta dos indivíduos.

O Estado brasileiro declara guerra ao Comando Vermelho: constrói a prisão Bangu Um especialmente para recolher traficantes, como José Carlos dos Reis Encina, o Escadinha, ataca pontos de venda de drogas, sobe morros e com isso logra sustentar um conflito diário que mata soldados de ambos os lados, além da população favelada, sem arranhar o tráfico de drogas na cidade do Rio de Janeiro, muito menos os circuitos da economia internacional do tráfico que perpassam o território nacional. De fato, os esforços do governo brasileiro em combater o tráfico industrial dos anos 80 (iniciativas que já despontam na seqüência de acordos celebrados nos anos 70 com os Estados limítrofes da região amazônica) ${ }^{10}$ acertavam o passo da política nacional antidrogas perante o novo cenário da repressão internacional ao narcotráfico.

No momento em que o Comando Vermelho crescia no Rio de Janeiro, o governo norte-americano passava a focalizar o tráfico de drogas de maneira ainda mais incisiva, transformando-o em "grande inimigo dos EUA". Em 1986, o presidente estadunidense Ronald Reagan edita a National Security Decision Directive on Narcotics and National Security (NSDD-221), documento no qual o governo norte-americano "oficializa sua percepção de que a principal ameaça aos Estados Unidos e ao hemisfério ocidental passara a residir na simbiose entre terrorismo de esquerda e narcotráfico, (...) a NSDD-221 'diagnosticava' o problema da 'narco-subversão' e expunha a necessidade imperiosa de que os Estados Unidos de defendessem (e defendessem o continente) da grande trama 'narcoterrorista'" (Rodrigues, 2001:215). Se desviaria em demasia da discussão atentar para as intrincadas relações dos Estados Unidos e o "narcopatrocínio" às guerrilhas de direita na América Central nestes mesmos anos, contudo, o que cabe frisar é o deslocamento da doutrina de se- 
gurança nacional norte-americana que se desenha com a declaração de Reagan. A justificativa maior para a intervenção estadunidense na América Latina iniciava um movimento que reporia no lugar do "combate ao comunismo" uma outra urgência. Quando fuzileiros navais norte-americanos ocupam a Cidade do Panamá e capturam o então presidente da república panamenha, Manuel Noriega, a acusação que pesava sobre ele já não era 'conspiração comunista', recorrente incriminação da guerra fria, mas um crime de nova ordem: "conspiração por tráfico de drogas".

A abdução de Noriega é retrato de um momento no qual o proibicionismo norte-americano havia recobrado fôlego. A Convenção de Viena, celebrada em 1988, atualizara a Convenção Única de 1961, encorpando as obrigações repressivas dos Estados signatários (entre eles o Brasil). A continuidade do governo republicano em Washington, encabeçado por George Bush, garantia a manutenção da diplomacia antidrogas, mas também, inaugurava nova fase na qual os EUA esforçaram-se em militarizar o combate ao narcotráfico no continente. Nas conferências presidenciais de Cartagena (1990) e San Antonio (1992), Bush propôs a seus colegas do México, Peru, Bolívia, Colômbia, Equador e Venezuela, que apoiassem a formação de uma força militar transnacional, coordenada pelos Estados Unidos, destinada a combater o narcotráfico no continente. Ao sugerir um exército formado por militares de todos os países envolvidos, a proposta de Bush tentava quebrar resistências dos presidentes latino-americanos e da opinião pública norte-americana. De um lado, uma força mista escamotearia a ingerência estadunidense, de outro, a partilha das responsabilidades militares não pareceria aos cidadãos norte-americanos que seus filhos seriam lançados em um "novo Vietnã". A estratégia, contudo, não é bem-sucedida; a força antidrogas continental não é formada, mas o investimento na idéia de repartir funções no combate ao narcotráfico permanece em novo período de ampliação da repressão em tempos de consenso continental.

\section{CONTROLE: REFORMAS E FLUXOS SIDERAIS}

Em 1990, o governo brasileiro propõe a criação do Sistema de Proteção da Amazônia (Sipam), projeto que incorporava ao tradicional discurso da segurança nacional a questão da segurança ecológica (defesa do patrimônio biológico). O Sipam seria o coordenador de políticas estatais para a região amazônica, ao concentrar a análise de dados obtidos pelo cruzamento de imagens captadas por sensoriamento remoto. A estrutura operacional idealiza- da para o Sipam foi o Sistema de Vigilância da Amazônia (Sivam), constituído por uma rede de satélites, radares fixos e computadores integrados por tecnologia de ponta em telecomunicações. A região amazônica, vazio histórico de autoridade estatal, passaria a ser alvo de uma nova modalidade de controle territorial: a teledetecção.

Os objetivos declarados do Sivam são o monitoramento da região amazônica para a proteção ambiental (identificação de áreas de desmatamento, previsões meteorológicas, monitoramento dos recursos hídricos e das riquezas do solo) e para a coerção das atividades clandestinas (extração de madeiras protegidas, contrabando de fármacos, garimpos ilegais e, em especial, ao tráfico de drogas). ${ }^{11}$ Idealizado para controle ostensivo da Amazônia brasileira, o Sivam seria apenas a quarta etapa do Projeto Cindacta $^{12}$ se o monitoramento da região amazônica não envolvesse questões políticas e estratégicas importantes como a vigilância ambiental (biotecnologia), a repressão ao narcotráfico e a possibilidade de concretização da posse definitiva do Estado brasileiro sobre um imenso território que sempre esteve por ser de fato conquistado. A proposta do Sivam evidenciou que, no pensamento sobre temas de segurança nacional, a importância geopolítica historicamente conferida à região do Prata (disputa por hegemonia regional com a Argentina) desloca-se para a Amazônia num momento em que o discurso ecológico prega a internacionalização da floresta tropical e que o narcotráfico apresenta ameaças à soberania tradicional (de forma direta, pela ocupação de espaços vazios de poder estatal e, indiretamente, pelo temor constante de uma intervenção norte-americana supostamente direcionada à guerra às drogas).

A vigilância desde o espaço sideral desenha-se, então, como técnica de gestão do território e dos indivíduos em permanente ação ainda que imperceptível. Das tentativas de ocupação e controle da Amazônia legal, que pode remontar às expedições de Rondon, à criação da zona franca de Manaus nos anos 60, à construção da Transamazônica nos 70 e ao projeto Calha Norte, dos 80, o Sivam ${ }^{13}$ surge como nova tentativa de apossamento da vastidão amazônica amparada na "premente necessidade" em se controlar os fluxos de atividades ilícitas na região. Após as polêmicas em torno da licitação para a compra dos radares e das disputas sobre o manejo das informações sigilosas que seriam geradas pelo sistema de vigilância, o gerenciamento de dados do Sivam é transferido, em 1995, para o Ministério da Aeronáutica, militarizando, sem subterfúgios, o projeto. ${ }^{14}$ Com previsão inicial para estar em 
operação parcial em 1998, o Sivam não deve rastrear a planície amazônica antes de 2002.

Além do rastreamento de ilegalidades proposto pelo Sivam, a década de 90 foi profícua, no que concerne ao combate ao narcotráfico, em tentativas de expurgo levadas a cabo nos meios políticos brasileiros. Em 1991, uma Comissão Parlamentar de Inquérito (CPI) é formada no Congresso Nacional para investigar a suposta participação de deputados e juízes com o tráfico de drogas. Grandes chefes não são desmascarados, redes internacionais não são desarticuladas, mas um parlamentar é cassado: Jabes Rabelo, deputado federal pelo Acre foi destituído do cargo por manter, segundo a Comissão, relações com traficantes de seu Estado natal. O Acre entra de novo no circuito das acusações parlamentares em 1996, quando o deputado e policial militar, Hildebrando Pascoal é acusado de comandar um grupo de extermínio a serviço de traficantes acreanos. $\mathrm{Na}$ esteira das investigações sobre o envolvimento do ex-governador do Acre Oleir Cameli (1995-1998) com o narcotráfico, chega-se novamente ao nome de Pascoal. Uma nova comissão de inquérito aberta em abril de 1999, conhecida como CPI do Narcotráfico, aponta Pascoal como líder de um grupo de traficantes com conexões no Brasil, Bolívia e Peru. O deputado é cassado e preso em seguida. A "meta-inquisição" das comissões parlamentares torna público o fato de que o Brasil não poderia mais ser tomado como um passivo "corredor de exportação" para a cocaína andina, mas que, ao contrário, contava efetivamente com centros consumidores importantes, redes de distribuição de drogas e uma intrincada conexão entre políticos, na esfera federal e estadual, juízes, roubos de cargas e caminhões e tráfico de cocaína e maconha. Constatações suficientes para soar o alarme de terror da opinião pública e o sensacionalismo da mídia; ambiente propício para movimentar a ciranda das reformas. Em 1998, o Decreto no 2.632 emenda a Lei de Tóxicos de 1976, criando a Secretaria Nacional Antidrogas (Senad), órgão ligado ao poder Executivo, que deveria coordenar as ações de combate ao tráfico e prevenção ao consumo de drogas no Brasil; em 1999, pouco após o término da CPI do Narcotráfico, a Senad coordena, com as forças armadas e a Polícia Federal, a Operação Mandacaru, que ao custo de 4 milhões de dólares prendeu camponeses e queimou plantações no chamado polígono da maconha em Pernambuco; no primeiro semestre de 2000, o governo federal, impelido pelo aumento dos índices de criminalidade no País, cria o Plano Nacional de Segurança Pública, tentativa de federalizar o combate ao crime, com o repasse de 1,5 bilhão de dólares para os Estados até 2002 (em adição ao plano, o Estado brasileiro cria o Subsistema de Inteligência vinculado à Agência Brasileira de Inteligência (Abin), encarregada de centralizar as análises de informações estratégicas). ${ }^{15}$

A "identificação" de parlamentares traficantes, juízes coniventes e consumidores em abundância justifica que o Estado proibicionista brasileiro acione dispositivos repressivos que, por sua vez, são atualizados por reformas legais e institucionais que zunem no mesmo diapasão do concerto internacional antidrogas.

\section{CONTROLE: ANTIGOS ALVOS E GRILHÕES}

\section{Jogral (Neo)liberal}

Em um congresso patrocinado, em 1989, pelo International Institute for Economy, centro de pesquisa sediado em Washington, o economista John Williamson apresentou um paper no qual afirmava haver, nas esferas administrativas norte-americanas e nos organismos financeiros internacionais (Fundo Monetário Internacional e Banco Mundial), uma impressionante coincidência nas recomendações formuladas ou pensadas para a América Latina. Pontos como o equilíbrio e austeridade fiscais, reforma previdenciária, corte nos gastos públicos, privatização de empresas estatais, estabilização monetária, desregulamentação dos mercados financeiros e de trabalho, eram conselhos recorrentes dirigidos aos governos latino-americanos, fato que fez com que Williamson identificasse um "consenso de Washington", que nada mais era do que a extrema convergência das diretrizes macro e microeconômicas destinadas aos países americanos. A sistematização operada por Williamson agradou as instituições em consenso e tornou-se uma espécie de cartilha a reger as reformas econômicas tomadas em uníssono pelos Estados latino-americanos como única via para o desenvolvimento de sociedades soltas no redemoinho da competitividade global.

\section{Jogral Democrático}

Realizada em Miami, entre os dias 09 e 11 de dezembro de 1994, a primeira Cúpula das Américas foi uma iniciativa do governo de Bill Clinton que reuniu chefes de Estado de todo o continente (excetuando-se Cuba) para discutir um futuro de bonança para as nações americanas. O documento final, chamado Pacto para o desenvolvimento 
e a prosperidade: democracia, livre-comércio e desenvolvimento sustentável nas Américas, ${ }^{16}$ é um compêndio de intenções que passam pela discussão acerca do papel da mulher nas sociedades, da proteção do meio ambiente para as gerações futuras, da erradicação da pobreza, da prosperidade por meio da liberdade comercial (lançando o projeto da Alca), da defesa dos direitos humanos, entre outras generalidades. No tópico "Plano de ação" há um subitem intitulado "A luta contra o problema das drogas ilícitas e delitos conexos", em que o texto investe em dois argumentos básicos: de início conclama os Estados do continente a aumentarem a fiscalização sobre transações financeiras suspeitas (e somente as "suspeitas", para o bem do livre fluxo de capitais) e a unirem esforços na interceptação das redes de lavagem de dinheiro; em seguida, o documento exorta que as nações americanas promovam ações coordenadas para destruir organizações do tráfico, substituir cultivos ilícitos por culturas alternativas, tratar dos "adictos", controlar a circulação de insumos químicos e incentivar encontros e acordos internacionais sobre controle de substâncias psicoativas (Arnaud, 1996:439).

Dando o tom a essas metas, está a idéia de que "os problemas das drogas ilícitas (...) levantam graves ameaças para as sociedades, as economias de livre mercado e as instituições democráticas do hemisfério (...) o uso de drogas impõe enormes custos sociais e as organizações criminosas põe em perigo a segurança de nosso povo através da corrupção, da intimidação e da violência" (Arnaud, 1996:438). O grande "flagelo" moral, social e sanitário das drogas assume, assim, o caráter de "flagelo político" ao relacionar diretamente à existência do narcotráfico (em seus componentes "violência" e "corrupção") à fragilização das sociedades americanas e suas incipientes democracias.

Incorporada ao tema da manutenção da democracia no continente, a questão do combate ao tráfico de drogas ganha positividade como peça da grande unanimidade presente na uniformização dos valores políticos, morais e sociais nas Américas. Para assumir, contudo, essa qualidade de liga consensual, o discurso da "guerra às drogas" deve transmutar-se uma vez mais. A ênfase na militarização unilateral de George Bush mostrou-se contraproducente, talvez por ser explícita demais; desse modo, uma readequação programática fazia-se necessária. O próprio documento da Cúpula das Américas nos dá sinais da política desenvolvida pelo governo Clinton ao sustentar que "frente a todos os problemas (relacionados às drogas) é necessário um enfoque integrado que inclua o respeito à soberania nacional (...) por esse motivo, requer-se uma es- tratégia hemisférica ampla e coordenada para reduzir o consumo e a produção de estupefacientes". No lugar da militarização de Bush, Clinton propõe a "responsabilidade compartida", tática hábil que ao mesmo tempo eleva o combate ao narcotráfico ao topo da agenda continental e nacional dos Estados americanos.

Todos os Estados são enredados no esforço de combate a um "perigo que concerne e pertence a todos" e que exige "movimentos sincronizados". O próprio Plano Colômbia espelha essa pequena metamorfose de prática e discurso ao prever um aporte de 7,5 bilhões de dólares para combate ao narcotráfico (combate apresentado como a soma de iniciativas militares e ajuda econômica ao campesinato), dos quais 1,3 bilhão de dólares provêm dos EUA e o restante reparte-se entre recursos do governo colombiano, da União Européia, do Japão e de outros organismos internacionais. $\mathrm{O}$ envio de instrutores militares estadunidenses e a venda de equipamento bélico norteamericano entram de roldão numa iniciativa de "caráter amplo" e que se aninha na nova idéia de partilha de responsabilidades. ${ }^{17}$ O Plano Colômbia ativa, também, o governo brasileiro que, declarando receio de que o combate ao narcotráfico no país vizinho force o deslocamento de laboratórios de refino de cocaína e de acampamentos de traficantes para a Amazônia Legal, montou uma operação (a Cobra, de Colômbia/Brasil), ação conjunta da Polícia Federal, Forças Armadas e Agência Brasileira de Inteligência que iniciou, no final de 2000, a montagem de acampamentos ao longo da fronteira colombiana. Além do Sivam, patrulha sideral da Amazônia, o combate ao narcotráfico inspira a ocupação tradicional da selva tropical, num projeto com orçamento previsto em 6 milhões de dólares até 2003.

A aura intervencionista estadunidense esmorece ao tempo em que a política antidrogas norte-americana conquista uma importante vitória: os Estados latino-americanos tomam como suas as linhas gerais da política repressiva de Washington, reproduzindo no local uma postura proibicionista que perde as feições norte-americanas para tornar-se continental. Essa incorporação das diretrizes antidrogas (agora não mais estadunidenses, mas americanas), todavia, não é de maneira alguma desprovida de positividades para os governos americanos. Pelo contrário, a aceitação da agenda norte-americana e as modificações legais levadas a cabo para tanto, incrementam, significativamente, a capacidade governamental em intervir na sociedade em busca dos "facínoras negociantes de venenos proibidos”. Há, de fato, uma sobreposição entre os 
que são capturados pelas forças de segurança dos Estados antidrogas e lançados nas engrenagens do sistema penitenciário e os tradicionais segmentos sociais tidos como "perigosos" e "desviantes". Situação que não revela propriamente uma novidade, uma vez que repressão ao tráfico recaiu desde princípios do século XX sobre "incontroláveis marginais", quer eles fossem chineses e mexicanos nos EUA, quer fossem negros e mestiços no Brasil. O crescimento do número de pessoas encarceradas na Europa e nos Estados Unidos, nos últimos decênios do século XX, característica que emerge como "tática de contenção" à massa de "novos pobres" dos ex-welfare states, utiliza como instrumento para a captura desses "alvos instabilizadores", justamente, a perseguição às drogas. Uma análise atenta das estatísticas de países da União Européia e dos Estados Unidos ${ }^{18}$ não tardaria em apresentar correlações diretas entre o avanço da penalização sobre a população pobre ou "desassistida" e o aumento das condenações relacionadas às drogas ilícitas. Mesmo em países que nunca contaram com uma malha de assistência social, como o Brasil, o recrudescimento das medidas punitivas e do uso do encarceramento como medida correcional privilegiadas acompanha a paranóia da segurança pública que alimenta o temor social e os clamores por tolerância zero (Wacquant, 2001).

$\mathrm{Na}$ esteira da defesa de novas verdades, "nortes" a se seguir e aspirar, o combate ao narcotráfico surge como ponto nevrálgico no qual residem ameaças à ordem e à prosperidade do planeta. Este início do século XXI, tão fértil em novas utopias requentadas como a do Grande Estado pluralista (projetado no modelo europeu) e a da panacéia do mercado livre redentor, assiste ao investimento que a comunidade de Estados faz na manutenção do expurgo à diferença, ao desvio, à alteridade. Nesse ambiente "transnacionalizado", alimenta-se a existência de um inimigo também volátil e sem pátria. O narcotráfico, filhote de uma ilegalidade que gera positividades incalculáveis para o lado legal da economia global, é crime de seu tempo. Nos fluxos de capital do livre mercado mundial circulam os bilhões de narcodólares; os satélites que vigiam avionetas orbitam ao lado dos que transferem fortunas arrecadadas no tráfico; as armas que combatem as organizações narcotraficantes também as equipam; e os negociadores de drogas capturados no Brasil são mais semelhantes aos norte-americanos e europeus do que em geral se pensa. Transitamos, assim, em um jogo de similitudes e quase-coincidências, em tempos nos quais a hegemonia dos consensos também se traduz em eficazes estratégias de controle social.

\section{NOTAS}

1. No momento em que se elabora esta reflexão, assiste-se aos ataques anglo-americanos ao regime afegão do Taleban, em represália aos atos terroristas de setembro em Nova Iorque e Washington. Desde o início da campanha contra os talebans, emergiram na imprensa informações que vinculavam o patrocínio ao regime extremista, e mesmo às supostas ações do saudita Osama bin Laden, ao tráfico de heroína e ópio. A discussão pormenorizada sobre o tráfico na Ásia Central e suas conexões com o financiamento de insurreições locais se deslocaria da investigação no campo americano, foco do presente artigo. Todavia, é importante notar que a associação entre 'terrorismo islâmico' e narcotráfico é útil aos discursos governamentais proibicionistas enquanto atrelagem entre dois "males ao Ocidente"; dois "flagelos" que merecem ser extirpados do mundo pelas cruzadas ("contra o terror" e "contra as drogas"); cruzadas que são, vale lembrar, guerras santas cristãs. Estas reflexões, num momento posterior, serão aprofundadas.

2. Faz-se referência aqui à existência de corpos de idéias que se disseminam pelo globo no final do século XX e que criam redes de convergência de opiniões, posturas e demandas em torno de temas que se internacionalizam. A defesa dos direitos humanos, da democracia como valor político máximo, do patrimônio ecológico, dos direitos das minorias, entre outros, são, pois, "regimes internacionais" que encadeiam visões de mundo e constroem valores que se universalizam como "verdades sãs para a humanidade".

3. No começo do século XX diversas agremiações puritanas estavam ativas nos Estados Unidos reivindicando do Estado medidas coercitivas em relação aos "vícios e degenerações sociais", identificados, basicamente, na tríade jogo-álcool-luxúria. São exemplos dessas associações a Anti-saloon League, fundada em 1893, o Proibition Party, de 1869, e a Sociedade para a Supressão do Vício, de 1873 (McAllister, 2000 e Rodrigues, 2001).

4. Segundo autores como McAllister (2000), Passetti (1991) e Labrousse (2000), a Conferência de Xangai não pode ser entendida sem se computar como a postura proibicionista dos EUA contribuía para os interesses comerciais norte-americanos na Ásia. A região estava, no começo do século XX, sob domínio político e econômico de potências européias, principalmente da Inglaterra; domínio que se exercia, em larga medida, no comércio de ópio. Atacar o tráfico de ópio era, então, uma tática (que não deixava de estar amparada em preceitos morais) para minar um dos pilares do colonialismo europeu no continente.

5. A Harrison Narcotic Act foi a primeira lei de controle efetivo do Estado sobre drogas editada nos Estados Unidos. Assim, caberia a órgãos especiais do Estado a avaliação do potencial medicinal de qualquer substância, ato que levaria ao seu consumo controlado (por meio de receitas médicas obrigatórias) ou proibição expressa.

6. Houve, no período entreguerras, três reuniões plenipotenciárias, sobre controle de drogas, celebradas em Genebra sob os auspícios da Liga das Nações e patrocínio dos EUA: a primeira em 1925, a segunda em 1931 e a última em 1936. Os dois primeiros encontros produziram documentos que complexificavam as estruturas internacionais de registro sobre o comércio legal de drogas controladas (a parcela destinada ao "uso terapêutico") e que exortavam os signatários a construir em seus países instituições repressivas e burocráticas nos moldes estadunidenses. A convenção de 1936 foi a primeira específica sobre repressão ao tráfico internacional de drogas; nela a delegação norte-americana comandada pelo chefe do combate às drogas nos Estados Unidos, Harry Anslinger (1892-1975), exigiu a total criminalização do comércio internacional de substâncias psicoativas (ópio, opiáceos e cocaína). Diante da resistência de países produtores, a delegação estadunidense não assina o documento final, enfraquecendo definitivamente a aplicabilidade do tratado.

7. A Convenção Única de 1961 aglutinava acordos anteriores, ampliava o alcance das medidas de controle das drogas ilegais e burocratizava a estrutura regulatória internacional, além de ditar listas de drogas 
proibidas. O Brasil, signatário do tratado, incorpora suas determinações em 1964 pelo Decreto n ${ }^{\circ} 54.216$ de 27 de agosto de 1964.

8. Um projeto de reforma da Lei de Tóxicos transita pelo Congresso Nacional, contando com amplo apoio das bancadas governistas e de oposição, e alimentando, uma vez mais, o fluxo das readequações legais e dos pequenos reajustes repressivos.

9. Imagem utilizada por Gugliotta (1995).

10. Na segunda metade da década de 70, o governo brasileiro celebrou "Convênios de Assistência Recíproca para a Repressão do Tráfico Ilícito de Drogas que Produzem Dependência" com Peru (1975), Bolívia (1977) e Venezuela (1977). Os textos, idênticos em seus termos, são manifestações de intenção e comprometimento dos Estados em estreitarem os laços de cooperação bilateral e reforçarem o combate ao tráfico e uso de drogas proibidas em seus próprios territórios.

11. Documento da Presidência da República, 1994, citado por Brigagão (1996:53).

12. O Centro Integrado de Defesa Aérea e Controle do Tráfego Aéreo (Cindacta) é um projeto desenvolvido desde 1981 pelo Ministério da Aeronáutica para o monitoramento do espaço aéreo brasileiro. Três etapas do Cindacta estão em funcionamento, rastreando as regiões Sul, Sudeste e Centro-Oeste do País.

13. A estrutura do Sivam previa instalação de três centros regionais (em Manaus, Belém e Porto Velho), circundados de subcentros operacionais responsáveis pelo gerenciamento dos dados e das imagens captadas. Por sua vez, estes centros estariam conectados ao Centro de Coordenação Geral, locado em Brasília com a Secretaria de Assuntos Estratégicos.

14. O governo brasileiro divulga, em 1993, que não haveria licitação pública para escolher o consórcio responsável pelo projeto. A convocação para o Sivam foi distribuída pelas embaixadas em Brasília, resultando em 12 propostas para fornecimento de equipamentos para o projeto. Como a questão do monopólio do controle das informações estratégicas apresentava-se como cerne das preocupações estatais, a empresa Esca, de capital brasileiro, foi escolhida de antemão para ser a gerenciadora nacional do Sivam. Analisadas as propostas, restaram dois consórcios em disputa: o grupo Raytheon, dos Estados Unidos, e o Thomsom/Alcatel, da França. Começa, então, uma disputa diplomática envolvendo representantes dos governos francês e norte-americano que culmina na denúncia, por parte da CIA, de que o consórcio francês havia subornado altos funcionários do governo brasileiro. O mal-estar diplomático gerado, não impediu a vitória do grupo Raytheon, com o projeto orçado em 1,4 bilhão de dólares. Além dos centros regionais previstos; o projeto aprovado prevê a instalação de 14 radares fixos, oito móveis (aéreo-transportados em aviões Embraer de fabricação brasileira), além da elaboração de um software específico para o cruzamento de informações e imagens captadas por diversos satélites artificiais.

O sigilo que envolveu a contratação da Raytheon, a ausência de concorrência pública e de transparência na divulgação das informações sobre o Sivam por parte do governo, as suspeitas de ingerência norteamericana (pressões diplomáticas a favor do consórcio estadunidense) e a obtusidade quanto ao gerenciamento de informações estratégicas levantaram suspeitas sobre a lisura do projeto, causando acalorada polêmica na opinião pública e nos círculos políticos da capital federal. Em 1995, veio o afastamento da Esca de suas funções de mantenedora nacional do Sivam, ao se descobrir que nove funcionários da Comissão de Implantação do Sistema de Controle do Espaço Aéreo (órgão do Ministério da Aeronáutica envolvido na implantação do projeto) estavam ligados à Esca como funcionários ou prestadores de serviço. A crise política gerada com tal revelação quase obriga o presidente Fernando Henrique Cardoso a cancelar o contrato com a Raytheon. A solução para o impasse foi o deslocamento da função de operador nacional da tecnologia fornecida pela Raytheon para o Ministério da Aeronáutica.
15. A polêmica em torno da Abin centra-se no fato de que a esquerda brasileira teme a rearticulação do Sistema de Inteligência (SNI) operante na ditadura militar (1964-1985). Contudo, a Abin sustenta um discurso "democrático" segundo o qual serão combatidos os novos "inimigos nacionais": o crime e a violência (podendo ler, nas entrelinhas, narcotráfico).

16. Texto na íntegra em Arnaud (1996:427-461)

17. Isto sem entrar na espinhosa questão levantada pelas Forças Armadas Revolucionárias da Colômbia (Farc) e o Exército de Libertação Nacional (ELN), guerrilhas marxistas do país, de que o Plano Colômbia seria uma escusa para paramentar o exército colombiano, fortalecendo uma futura ofensiva contra os insurretos.

18. Análises acuradas sobre a relação entre o crescimento de condenações relacionadas às drogas ilegais e a procedência social e étnica destes condenados podem ser encontradas em Christie (1998), Minhoto (2000), Szasz (1992) e Wacquant (2001).

\section{REFERÊNCIAS BIBLIOGRÁFICAS}

AMBOS, K. Control de drogas. Bogotá, Ediciones Jurídicas Gustavo Ibañez, 1998.

ARNAUD, V. Mercosur, Unión Europea, NAFTA y los procesos de integración regional. Buenos Aires, Abeledo-Perrot, 1996.

BRIGAGÃO, C. Inteligência e marketing: o caso Sivam. Rio de Janeiro, Record, 1996.

CARNEIRO, B. A vertigem dos venenos elegantes. Dissertação de Mestrado. São Paulo, PUC-SP, 1993.

CHRISTIE, N. A indústria do controle do crime. São Paulo, Forense, 1998.

DOWBOR, L.; IANNI, O.; RESENDE, P. (orgs.). Desafios da globalização. Petrópolis, Vozes, 1998.

ESCOHOTADO, A. Historia de las drogas. Madri, Alianza Editorial, 1998, v.2-3.

FOUCAULT, M. Resumo dos cursos do Collège de France. Rio de Janeiro, Jorge Zahar, 1997.

. Microfísica do poder. Rio de Janeiro, Graal, 1998.

. A verdade e as formas jurídicas. Rio de Janeiro, Nau Editora/PUC-Rio, 1999.

GUGLIOTTA, G. "Los cárteles colombianos y cómo detenerlos". In: SMITH, P. (org.). El combate a las drogas en América. México, Fondo de Cultura Económica, 1995.

KRAUTHAUSEN, C. e SARMIENTO, L. Cocaína e Co.: un mercado ilegal por dentro. Bogotá, Tercer Mundo, 1991.

LABROUSSE, A. Drogues, un marché des dupes. Paris, Editions Alternatives, 2000.

McALLISTER, W. Drug diplomacy in the twentieth century. Nova York, Routledge, 2000.

MARSHALL, J. e SCOTT, P. Cocaine politics: drugs, armies and the CIA in Central America. Los Angeles, Ucla Press, 1991.

MÉDICI, S. A nova lei antitóxicos. São Paulo, Tilibra, 1972.

MIGUEL, E. e PASQUINI, G. Blanca y radiante: máfias, poder y narcotráfico en la Argentina. Buenos Aires, Espejo de la Argentina, 1995.

MINHOTO, L. Privatização de presídios e criminalidade: gestão da violência no capitalismo global. São Paulo, Max Limonad, 2000.

PASSETTI, E. Das 'fumeries' ao narcotráfico. São Paulo, Educ, 1991. 
. "Narcotráfico, militarização e legalização". Revista Direito para Todos. São Paulo, ano 1, n.2, 1994, p.15-25.

ROBEY, J. “A war on drugs or a war on minorities?”. In: NAGEL, S. (org.). Handbook of global legal policy. Nova Iorque, Marcel Dekker Inc., 2000.

RODRIGUES, T. Política e drogas nas Américas. Dissertação de Mestrado. São Paulo, PUC-SP, 2001.

SZASZ, T. Nuestro derecho a las drogas. Barcelona, Anagrama, 1992.
WACQUANT, L. As prisões da miséria. Rio de Janeiro, Jorge Zahar, 2001.

Thiago M. S. Rodrigues: Coordenador do curso de Relações Internacionais da Faculdade Santa Marcelina, Assistente de Pesquisa do Cebrab e Pesquisador do Núcleo de Sociabilidade Literária da PUC-SP (thiago_msr@hotmail.com). 